\title{
Histopathology of breast cancer in young women in relation to use of oral contraceptives
}

\author{
NAOMI MILLER, ${ }^{*}$ K McPHERSON, $†$ LESLEY JONES, $\dagger$ M VESSEY $†$ \\ From the *Hedley Atkins Unit, Guys Hospital, London, and the $\dagger$ Department of Community Medicine and \\ General Practice, Radcliffe Infirmary, Oxford
}

SUMMARY A detailed review was made of the histopathology of 227 tumours taken from 261 women under 45 years of age with breast cancer. The tumours were classified as follows: whether oral contraceptives had been used at any time; and whether oral contraceptives had been used before first term pregnancy. All analyses were adjusted for the effects of age. Overall, $201(88 \cdot 5 \%)$ of tumours were infiltrating ductal in type, $19(8 \cdot 4 \%)$ were infiltrating lobular, and seven $(3 \cdot 1 \%)$ were in situ ductal. Of the infiltrating ductal tumours, $28(14 \%)$ were grade I, $88(44 \%)$ grade II, and $84(42 \%)$ grade III. Various other tumour characteristics were also examined (per cent of carcinoma in situ, lymphatic permeation, necrosis, lymphoplasmocytic reaction and tumour edge). None of the histopathological features assessed showed any significant association with oral contraceptive use. Some characteristics of the areas of breast tissue adjacent to the tumours were also studied. The degree of cyst formation was considerably less pronounced in those using oral contraceptives before first term pregnancy than in those not doing so.

In 1983 we reported the preliminary findings in an epidemiological study of 247 women with primary breast cancer and a like number of matched control women, all of whom were under 45 years of age. ' There was a strong association between use of oral contraceptives before first term pregnancy and risk of breast cancer (relative risk for one to 12 months' use, 1.2; for 13-48 months' use, 1.7; for 49 or more months' use, 3.1). More recently, the final results of this study were published based on 351 case-control pairs aged under 45 years. ${ }^{2}$ The findings previously reported on oral contraceptive use before first term pregnancy were replicated but no overall association was found between use of oral contraceptives and risk of breast cancer.

Shortly after the publication of our preliminary report we decided to undertake a histopathological review of as many as possible of the neoplasms in the 261 women with primary breast cancer who had by then been included in the study. We judged this to be important because the study had produced worrying findings and we considered that histopathological data might help in the interpretation of the association between early use of oral contraceptives and breast cancer.

\section{Subjects and methods}

The 261 women with breast cancer were all married Accepted for publication 16 November 1988 but otherwise formed a consecutive series identified at eight hospitals in London and Oxford between 1980 and 1983. Each woman had been interviewed by a research nurse who had obtained a comprehensive history including details of oral contraceptive use. We attempted to recover histological material from the primary tumour for each woman, but failed to obtain cooperation at one hospital where 19 women had been treated, thus reducing the sample to 242 . Of these, no histological material could be obtained from the primary tumour for 12 , while four had had only a Trucut biopsy specimen taken, which enabled us to confirm the diagnosis of malignancy but did not permit detailed histological evaluation. Three biopsy specimens showed no conclusive evidence of malignancy, another included insufficient material for assessment, while one woman had an angiosarcoma of the breast. Four women had multiple primary carcinomas with a total of 10 tumours between them. Accordingly, some degree of assessment was possible for 227 carcinomas in 221 women. The amount of material available for review varied widely from case to case, but in all at least one representative section of the tumour was examined. The assessment of the material was undertaken by one of us (NM) in the absence of information about contraceptive use. After confirming the diagnosis of carcinoma the following features were assessed:

(i) Histological type The tumours were typed as infiltrating ductal or infiltrating lobular carcinoma. In 
two tumours distinct architectural and cytological patterns of both ductal and lobular carcinoma were observed in the same neoplasm. These tumours were designated "mixed" carcinomas. Among the infiltrating ductal carcinomas the following histological subtypes were recognised: (a) medullary and atypical medullary carcinoma; (b) colloid carcinoma; (c) cribriform carcinoma; (d) tubular carcinoma. The term "infiltrating ductal carcinoma not otherwise specified (NOS)" was used to designate those infiltrating ductal carcinomas which showed no specific subtype pattern.

(ii) Histological grade This was assessed only for infiltrating ductal carcinomas. The method used was that of Bloom and Richardson, ${ }^{3}$ except that mitotic rate was estimated using criteria outlined by Elston ${ }^{4}$ instead of assessment of hyperchromatic and mitotic nuclei.

(iii) Proportion of carcinoma in situ This was assessed on a percentage basis within the area of tumour reviewed. Six groups were recognised: $0 \%, 1-24 \%$, $25-49 \%, 50-74 \%, 75-99 \%, 100 \%$ (pure carcinoma in situ).

(iv) Lymphatic permeation This was assessed on a scale of $0-3$.

(v) Necrosis This was assessed on a scale of $0-3$.

(vi) Lymphoplasmocytic reaction This was assessed on a scale of $0-3$.

(vii) Tumour edge Three categories were recognised: pushing; infiltrating; mixed.

(viii) Adjacent breast Where possible, seven features were evaluated and quantitated on a scale of 0-3. These were apocrine metaplasia, apocrine hyperplasia, cyst formation, blunt duct adenosis, epithelial hyperplasia, sclerosing adenosis, and atypical lobular hyperplasia. The features were assessed only on sections that also included tumour, not on additional sections from mastectomy specimens as these were received in only a few cases. Atypical ductal hyperplasia was not assessed; it should be noted that the histological work was started before Page et al ${ }^{\mathrm{s}}$ published their criteria for the diagnosis of this condition.

In the statistical analysis the histopathological findings were tabulated according to two different classifications of oral contraceptive use: (i) oral contraceptives used at some time $v$ oral contraceptives never used at any time; (ii) oral contraceptives used before first term pregnancy $v$ oral contraceptives not used before first term pregnancy. Finer subdivisions of the data were also examined, but the numbers were too small for evaluation and the results are not reported here.

Of the 221 women included in the analysis, 52 were aged between 25 and 34, 48 were aged between 35 and 39 , and 121 were aged between 40 and 44 . Users of oral contraceptives were, of course, younger on average than non-users. Accordingly, all the percentages shown in the tables are adjusted for age, using direct standardisation and grouping of the women in the three age categories defined above.

\section{Results}

The results of the histopathological review of the 227 tumours are given in tables 1-4. We decided that it would be simpler and more informative to base the results on tumours rather than on women, although the difference between the two approaches is obviously very minor.

Table 1 shows that the carcinomas occurring in pill users were a little less often of the infiltrating ductal NOS type than those occurring in non-users; conversely, tumours of other types were relatively more common in pill users than in non-users. In particular, six of seven in situ ductal cancers $(86 \%)$ and 14 of 19 infiltrating lobular cancers ( $74 \%$ ) occurred among the $145(64 \%)$ of women who had at some time used oral contraceptives. The distributions of the different histological types of cancer did not vary significantly, however, when pill users and non-users were compared (this was true both for pill use at any time and for use before first term pregnancy).

The crude data on histological grade of tumour suggested a more unfavourable distribution among pill users than among non-users. Adjustment of the figures for the effect of age, however, yielded the unremarkable percentages shown in table 2.

Again, although the data on other tumour characteristics given in table 3 show considerable variation, no clear patterns are apparent and there are no significant trends in relation to use of oral contraceptives, either at any time or before first term pregnancy.

Table 1 Histological type of tumour in relation to oral contraceptive use (numbers observed with age adjusted percentages given in parentheses)

\begin{tabular}{|c|c|c|c|c|}
\hline \multirow{3}{*}{$\begin{array}{l}\text { Histological type of } \\
\text { tumour }\end{array}$} & \multicolumn{4}{|c|}{ Oral contraceptive use: } \\
\hline & \multicolumn{2}{|l|}{ At any time } & \multicolumn{2}{|c|}{$\begin{array}{l}\text { Before first } \\
\text { term pregnancy }\end{array}$} \\
\hline & Yes & No & Yes & No \\
\hline $\begin{array}{l}\text { Infiltrating ductal: } \\
\text { NOS } \\
\text { Medullary } \\
\text { Cribriform } \\
\text { Tubular } \\
\text { Colloid } \\
\text { In situ ductal } \\
\text { Infiltrating lobular }\end{array}$ & $\begin{array}{c}113(76 \cdot 6) \\
6(4 \cdot 1) \\
1(0 \cdot 8) \\
3(2 \cdot 3) \\
2(1 \cdot 7) \\
6(4 \cdot 3) \\
14(10 \cdot 2)\end{array}$ & $\begin{array}{c}72(88 \cdot 8) \\
2(2 \cdot 0) \\
1(1 \cdot 5) \\
1(1 \cdot 0) \\
0(0.0) \\
1(1 \cdot 5) \\
5(5 \cdot 2)\end{array}$ & $\begin{array}{c}58(73.7) \\
4(6.1) \\
1(2.9) \\
1(1.2) \\
1(2.9) \\
2(3.6) \\
6(9.6)\end{array}$ & $\begin{array}{r}127(84 \cdot 2) \\
4(2 \cdot 3) \\
1(0.7) \\
3(1.6) \\
1(0.5) \\
5(3.8) \\
13(6.9)\end{array}$ \\
\hline Total & $145(100 \cdot 0)$ & $82(100 \cdot 0)$ & $73(100 \cdot 0)$ & $154(100 \cdot 0)$ \\
\hline
\end{tabular}

Note Two cancers of "mixed" ductal and lobular type were classified with the ductal tumours. 
Table 2 Histological grade of infiltrating ductal tumours in relation to oral contraceptive use (numbers observed with age adjusted percentages given in parentheses)

\begin{tabular}{|c|c|c|c|c|}
\hline \multirow[b]{3}{*}{ Grade } & \multicolumn{4}{|c|}{ Oral contraceptive use: } \\
\hline & \multicolumn{2}{|l|}{ At any time } & \multicolumn{2}{|c|}{ Before first term pregnancy } \\
\hline & Yes & No & Yes & No \\
\hline $\begin{array}{l}\text { I } \\
\text { II } \\
\text { III }\end{array}$ & $\begin{array}{l}14(11.8) \\
58(47.8) \\
52(40.4)\end{array}$ & $\begin{array}{l}14(17 \cdot 2) \\
30(38 \cdot 8) \\
32(44 \cdot 0)\end{array}$ & $\begin{array}{r}5(10 \cdot 6) \\
28(48 \cdot 0) \\
31(41 \cdot 4)\end{array}$ & $\begin{array}{l}23(15 \cdot 8) \\
60(42 \cdot 0) \\
53(42 \cdot 2)\end{array}$ \\
\hline Total & $124(100 \cdot 0)$ & $76(100 \cdot 0)$ & $64(100 \cdot 0)$ & $136(100 \cdot 0)$ \\
\hline
\end{tabular}

Note One infiltrating ductal cancer was not graded.

The final set of data, concerning the characteristics of the adjacent breast tissue, are given in table 4 . The figures for apocrine metaplasia are remarkable in that the specimens graded $2+$ are considerably in excess in the group using oral contraceptives when considering pill use at any time while the reverse is true when considering pill use before first term pregnancy. This pattern seems likely to reflect chance. Perhaps not surprisingly, the figures for apocrine hyperplasia show a similar, but less extreme, pattern. Of the remaining data, those for cyst formation are the most interesting; this seems to be much less common in those using oral contraceptives before first term pregnancy than in those not doing so.
Table 3 Other tumour characteristics in relation to oral contraceptive use (numbers observed with age adjusted percentages given in parentheses)

\begin{tabular}{|c|c|c|c|c|}
\hline \multirow[b]{3}{*}{ Characteristic } & \multicolumn{4}{|c|}{ Oral contraceptive use } \\
\hline & \multicolumn{2}{|c|}{ At any time } & \multicolumn{2}{|c|}{$\begin{array}{l}\text { Before first } \\
\text { term pregnancy }\end{array}$} \\
\hline & Yes & No & Yes & No \\
\hline \multicolumn{5}{|c|}{ Percent carcinoma in situ (227 assessed)* } \\
\hline 0 & $33(23 \cdot 3)$ & $16(18 \cdot 4)$ & $15(22 \cdot 8)$ & $34(22 \cdot 1)$ \\
\hline $1-49$ & $92(62.9)$ & $60(72 \cdot 2)$ & $47(60.9)$ & $105(67.4)$ \\
\hline 50-99 & $14(9 \cdot 5)$ & $5(7.9)$ & $9(12 \cdot 7)$ & $10(6 \cdot 7)$ \\
\hline $100-$ & $6(4 \cdot 3)$ & $1(1 \cdot 5)$ & $2(3 \cdot 6)$ & $5(3 \cdot 8)$ \\
\hline \multicolumn{5}{|c|}{ Lymphatic permeation ( 223 assessed) } \\
\hline 0 & $105(75 \cdot 0)$ & $61(74 \cdot 2)$ & $47(68 \cdot 3)$ & $119(77 \cdot 1)$ \\
\hline 1 & $15(10 \cdot 4)$ & $12(16.0)$ & $11(14.9)$ & $16(10.9)$ \\
\hline 2 & $15(9 \cdot 4)$ & $5(7 \cdot 0)$ & $10(11 \cdot 8)$ & $10(8 \cdot 2)$ \\
\hline 3 & $7(5 \cdot 2)$ & $3(2 \cdot 8)$ & $3(5 \cdot 0)$ & $7(3 \cdot 8)$ \\
\hline \multicolumn{5}{|c|}{ Necrosis (220 assessed) } \\
\hline 0 & $99(72 \cdot 6)$ & $62(77 \cdot 3)$ & $46(73 \cdot 1)$ & $115(76 \cdot 2)$ \\
\hline 1 & $15(10.5)$ & $9(11 \cdot 7)$ & $8(6 \cdot 9)$ & $16(10.9)$ \\
\hline 2 & $10(6 \cdot 5)$ & $2(1.9)$ & $6(5 \cdot 6)$ & $6(3 \cdot 6)$ \\
\hline 3 & $15(10.4)$ & $8(9 \cdot 1)$ & $10(14 \cdot 4)$ & $13(9 \cdot 3)$ \\
\hline \multicolumn{5}{|c|}{ Lymphoplasmocytic reaction ( 220 assessed) } \\
\hline 0 & $34(25 \cdot 2)$ & $17(19 \cdot 8)$ & $18(34 \cdot 2)$ & $33(22 \cdot 1)$ \\
\hline 1 & $49(35.0)$ & $36(50 \cdot 7)$ & $23(27 \cdot 6)$ & $62(45 \cdot 3)$ \\
\hline 2 & $33(22 \cdot 8)$ & $16(16 \cdot 5)$ & $16(16 \cdot 3)$ & $33(20 \cdot 1)$ \\
\hline 3 & $23(17 \cdot 0)$ & $12(13.0)$ & $14(21 \cdot 8)$ & $21(12 \cdot 5)$ \\
\hline \multicolumn{5}{|c|}{ Tumour edge (214 assessed) } \\
\hline Pushing & $10(7 \cdot 2)$ & $1(1 \cdot 7)$ & $5(8 \cdot 1$ & $6(5 \cdot 7)$ \\
\hline $\begin{array}{l}\text { Infiltrating } \\
\text { Mixed }\end{array}$ & $\begin{array}{l}84(62 \cdot 2) \\
43(30 \cdot 6)\end{array}$ & $51(66 \cdot 5)$ & $40(60 \cdot 4)$ & $\begin{array}{l}95(65 \cdot 8) \\
43(28.5)\end{array}$ \\
\hline & $0 \cdot 6)$ & $25(31 \cdot 8)$ & $25(31 \cdot 4)$ & $43(28 \cdot 5)$ \\
\hline
\end{tabular}

*It was not possible to assess every characteristic for every tumour because of variation in the amount and quality of the material available.

Table 4 Adjacent breast in relation to oral contraceptive use (numbers observed ${ }^{*}$ with age adjusted percentages in parentheses)

\begin{tabular}{|c|c|c|c|c|c|}
\hline \multirow[b]{3}{*}{ Characteristic } & & \multicolumn{4}{|c|}{ Oral contraceptive use: } \\
\hline & & \multicolumn{2}{|l|}{ At any time } & \multicolumn{2}{|c|}{ Before first term pregnancy } \\
\hline & & Yes & No & Yes & No \\
\hline Apocrine metaplasia & $\begin{array}{l}0 \\
1 \\
2+\end{array}$ & $\begin{array}{l}81(71 \cdot 5) \\
18(16 \cdot 7) \\
12(11 \cdot 8)\end{array}$ & $\begin{array}{c}40(77 \cdot 6) \\
14(19 \cdot 5) \\
2(2 \cdot 9)\end{array}$ & $\begin{array}{c}49(79.8) \\
9(18.6) \\
1(1.6)\end{array}$ & $\begin{array}{l}72(71 \cdot 4) \\
23(17 \cdot 4) \\
13(11 \cdot 2)\end{array}$ \\
\hline Apocrine hyperplasia & $\begin{array}{l}0 \\
1 \\
2+\end{array}$ & $\begin{array}{c}99(87 \cdot 3) \\
8(7 \cdot 6) \\
5(5 \cdot 1)\end{array}$ & $\begin{array}{c}49(91 \cdot 5) \\
2(2 \cdot 9) \\
4(5 \cdot 6)\end{array}$ & $\begin{array}{c}57(95.1) \\
2(4.9) \\
0(0.0)\end{array}$ & $\begin{array}{c}91(85.5) \\
8(7 \cdot 7) \\
9(6.8)\end{array}$ \\
\hline Cyst formation & $\begin{array}{l}0 \\
1 \\
2+\end{array}$ & $\begin{array}{l}65(55.9) \\
23(20.5) \\
24(23.6)\end{array}$ & $\begin{array}{l}29(57 \cdot 3) \\
14(24 \cdot 0) \\
12(18 \cdot 7)\end{array}$ & $\begin{array}{c}44(72 \cdot 6) \\
10(18 \cdot 6) \\
5(8 \cdot 8)\end{array}$ & $\begin{array}{l}50(50 \cdot 0) \\
27(25 \cdot 8) \\
31(24 \cdot 2)\end{array}$ \\
\hline Blunt duct adenosis & $\begin{array}{l}0 \\
1 \\
2+\end{array}$ & $\begin{array}{l}89(78 \cdot 8) \\
11(9 \cdot 6) \\
12(11 \cdot 6)\end{array}$ & $\begin{array}{c}47(85.5) \\
6(11.6) \\
2(2.9)\end{array}$ & $\begin{array}{c}50(84 \cdot 7) \\
5(5 \cdot 6) \\
4(9 \cdot 7)\end{array}$ & $\begin{array}{l}86(79.0) \\
12(11.9) \\
10(9 \cdot 1)\end{array}$ \\
\hline Epithelial hyperplasia & $\begin{array}{l}0 \\
1 \\
2+\end{array}$ & $\begin{array}{l}81(71 \cdot 3) \\
21(19 \cdot 6) \\
10(9 \cdot 1)\end{array}$ & $\begin{array}{c}41(76.0) \\
9(16.4) \\
5(7.6)\end{array}$ & $\begin{array}{r}45(75 \cdot 1) \\
8(12.9) \\
6(12.0)\end{array}$ & $\begin{array}{c}77(73.0) \\
22(18 \cdot 7) \\
9(8 \cdot 3)\end{array}$ \\
\hline Sclerosing adenosis & $\begin{array}{l}0 \\
1+\end{array}$ & $\begin{array}{c}102(90.4) \\
10(9.6)\end{array}$ & $\begin{array}{r}48(86.4) \\
7(13.6)\end{array}$ & $\begin{array}{c}55(91 \cdot 2) \\
4(8.8)\end{array}$ & $\begin{array}{l}95(88.4) \\
13(11.6)\end{array}$ \\
\hline Atypical lobular hyperplasia & $\begin{array}{l}0 \\
1+\end{array}$ & $\begin{array}{c}112(100 \cdot 0) \\
0(0 \cdot 0)\end{array}$ & $\begin{array}{c}54(98 \cdot 5) \\
1(1 \cdot 5)\end{array}$ & $\begin{array}{c}59(100.0) \\
0(0.0)\end{array}$ & $\begin{array}{c}107(99 \cdot 3) \\
1(0 \cdot 7)\end{array}$ \\
\hline
\end{tabular}

*The material available was sufficient for assessment in only 167 cases. 


\section{Discussion}

A large number of epidemiological studies of the association between use of oral contraceptives and breast cancer have been published. These studies have been reviewed by McPherson et al $^{2}$ and by Vessey $e t$ $a l^{6}$ among a number of others. In general, the results have indicated that use of oral contraceptives by mature women is unrelated to risk of breast cancer, but considerable doubt remains about the effects of early pill use, especially before first term pregnancy. Thus the studies by Pike et al, ${ }^{7}$ Meirik et $a l^{8}$ and McPherson $e t \mathrm{al}^{2}$ have produced worrying findings in this respect, while the studies of Stadel et al ${ }^{9}$ and Paul et al ${ }^{10}$ have not. The data set which is the subject of this paper is one of those which has produced worrying findings, and for this reason we thought that a histopathological review of the cancers would be especially worthwhile.

Similar reviews seem to be sparse, and those that do exist have generally been conducted in a more restricted way than the present one. Penman reported on a single case of breast cancer occurring in a 27 year old woman using the pill." He noted prominent "colostrum corpuscles" in the intraduct element of the tumour and found the lymph node metastases to be composed of strikingly eosinophilic cells. He thought these "peculiar histological features" might be related to use of the pill. Fechner ${ }^{12}$ described a series of five breast cancers occurring in pill users under 35 years of age and noted no special features. Gould $e t$ al reported on another small series of cases in pill users (aged 24, 29, and 46) and found that all "had both lobular and ductal components, secretory activity and conspicuous mucopolysaccharides in the stroma". ${ }^{13}$ In addition, "the lesions were pleomorphic and diffuse and contained abundant lymphocytic infiltration". A larger study was reported later by Vessey et al ${ }^{14}$ of 31 breast cancers in pill users and 59 in non-users (all aged under $\mathbf{4 0}$ years). No points of distinction were found between the lesions from patients who had used oral contraceptives and those from patients who had not. A similar conclusion was reached in a review of the literature by Fechner ${ }^{15}$ and in a study of 77 cancers in pill users and 58 in non-users reported by the Royal College of General Practitioners. ${ }^{16}$ Matthews et al, however, found a series of 93 tumours occurring in pill users to be significantly better differentiated on average than a series of 93 tumours occurring in non-users. ${ }^{17}$ The two groups of women studied were matched for age and parity.

Our results must be added to those which are essentially negative although the (necessarily) small size of the sample studied makes it likely that only major differences between users and non-users of oral contraceptives would have been discernible. None the less we believe our study to be of special interest, not only because of the detailed way in which the review was conducted, but also because the material was derived from an epidemiological study which strongly suggested a positive association between early pill use and breast cancer.

We are particularly grateful to Dr Rosemary Millis for her guidance during the conduct of this study. We also thank the medical staff at the participating hospitals for allowing us to study patients under their care and Mrs M S Simmonds, Mrs E H Hilton, Mrs J Young, Mrs A Bateman and Mrs M McArthur for conducting interviews. The Imperial Cancer Research Fund kindly provided financial support.

\section{References}

1 McPherson K, Neil A, Vessey MP, Doll R. Oral contraceptives and breast cancer. Lancet 1983;ii:1414-5.

2 McPherson K, Vessey MP, Neil A, Doll R, Jones L, Roberts M. Early oral contraceptive use and breast cancer: results of another case-control study. Br J Cancer 1987;56:653-60.

3 Bloom HJG, Richardson WW. Histological grading and prognosis in breast cancer. Br J Cancer 1957;11:359-77.

4 Elston $\mathrm{CW}$. The assessment of histological differentiation in breast cancer. Aust-New Zealand J Surg 1984;54:11-5.

5 Page DL, Dupont WD, Rogers LW, Rados MS. Atypical hyperplastic lesions of the female breast. Cancer 1985;55: 2698-708.

6 Vessey MP. Oral contraceptives and breast cancer. IPP Med Bull 1987;21:1-2.

7 Pike MC, Henderson BE, Krailo MD, Duke A, Roy S. Breast cancer in young women and use of oral contraceptives: possible modifying effect of formulation and age at use. Lancet 1983;ii:926-30.

8 Meirik O, Lund E, Adami H-O, Bergstrom R, Christoffersen T, Bergsjo $P$. Oral contraceptive use and breast cancer in young women. Lancet 1986;ii:650-4.

9 Stadel BV, Rubin GL, Webster LA, Schlesselman JJ, Wingo PA. Oral contraceptives and breast cancer in young women. Lancet 1985;ii:970-3

10 Paul C, Skegg DCG, Spears GFS, Kaldor JM. Oral contraceptives and breast cancer: a national study. $\mathrm{Br}$ Med J 1986;293:723-6.

11 Penman HG. The effect of oral contraceptives on the histology of carcinoma of the breast. J Pathol 1970;101:66-8.

12 Fechner RE. Breast cancer during oral contraceptive therapy. Cancer 1970;26:1204-11.

13 Gould VE, Wolff M, Mottet NK. Morphologic features of mammary carcinomas in women taking hormonal contraceptives. Am J Clin Pathol 1972;57:139-43.

14 Vessey MP, Doll R, Sutton PM. Oral contraceptives and breast neoplasia: a retrospective study. $\mathrm{Br}$ Med J 1972;3:719-24.

15 Fechner RE. Influence of oral contraceptives on breast diseases. Cancer 1977;39:2764-71.

16 Royal College of General Practitioners. Breast cancer and oral contraceptives: findings in Royal College of General Practitioners Study. Br Med J 1981;282:2089-93.

17 Matthews PN, Millis RR, Hayward JL. Breast cancer in women who have taken contraceptive steroids. $\mathrm{Br}$ Med J 1981;282: 774-6.

Requests for reprints to: Professor M Vessey, Department of Community Medicine and General Practice, Gibson Laboratories Building, Radcliffe Infirmary, Oxford OX2 6HE, England. 